\title{
Correspondence
}

\section{Rectal ulcer associated with Levamisole}

Sir,

Levamisole is effective in rheumatoid arthritis, but side effects are common. Mouth ulcers occurred in 6 of 24 in the trial of Scott et al. (1978) and in 15 of 253 patients in another (Multicentre Study Group, 1978). A patient of ours developed an ulcer in the rectum and later mouth ulcers, a complication not yet reported.

He was aged 49 when rheumatoid arthritis begin in 1970 , and this was treated with aspirin and indomethacin. He relapsed in 1976 but responded to gold, which was stopped after a total of $1.2 \mathrm{~g}$ because of intractable diarrhoea. During another relapse levamisole $50 \mathrm{mg}$ daily was started in June 1977, increasing slowly, to $150 \mathrm{mg}$ daily. He again responded well, but 6 weeks after starting, the haemoglobin had fallen from $13 \cdot 3$ to $7.4 \mathrm{~g} / \mathrm{dl}$. He admitted recent slight rectal bleeding, and rectal examination revealed a $2 \mathrm{~cm}$ diameter ulcer $4 \mathrm{~cm}$ from the anus. Proctoscopy showed this to be bleeding. Biopsies showed non-specific appearances with no evidence of malignancy or of the fibrosis and fragmentation of the muscularis mucosae characteristically seen in solitary ulcer of the rectum. Levamisole was stopped after he had taken about $9 \mathrm{~g}$, and 2 months later the ulcer had healed. It was restarted at the same dosage at his request as his arthritis had deteriorated. Three months later he had a $0.5 \mathrm{~cm}$ ulcer on the soft palate and a similar one on the lower lip. Rectal examination and protoscopy showed that the rectal ulcer had recurred. Biopsies were histologically identical to those taken previously. Levamisole was again withdrawn and all 3 ulcers healed completely during the next 3 months. He has since taken indomethacin and the ulcers have not recurred.

There seems little doubt that levamisole caused both the mouth and rectal ulcers. However, he was given large daily doses of the drug, which has since been found to be effective at a dose of $150 \mathrm{mg}$ weekly (Di Perri et al., 1978), this now being the recommended amount. Side effects are less likely with this smaller dose but will still occur. Therefore proctoscopy should be considered when patients on this drug develop unexplained anaemia, particularly if mouth ulcers are present.

G. V. H. BRADby, M. F. Shadforth Queen Elizabeth Hospital, Birmingham B15 2TH

A. M. HOARE Wycombe General Hospital, High Wycombe, Bucks

\section{References}

Di Perri, T., Auteri, A., Pasini, F. L., and Mattioli (1978). A weekly oral dose of levamisole in the treatment of rheumatoid arthritis associated with E-rosette lymphocyte reduction. European Journal of Rheumatology and Inflammation, 1, 155-164.

Multicentre Study Group (1978). Levamisole in rheumatoid arthritis: a randomised double-blind study comparing two dosage regimens of levamisole with placebo. Lancet, 2 , 1007-1012.

Scott, J., Dieppe, P. A., and Huskisson, E. C. (1978). Continuous and intermittent levamisole: a controlled trial. Annals of the Rheumatic Diseases, 37, 259-261.

\section{Dermatitis herpetiformis and rheumatoid arthritis}

Sir,

The abstract by Davies et al. (1978) underlines the interesting association between dermatitis herpetiformis and several disorders of presumed immune origin. Recently we have noted the coexistence of rheumatoid arthritis and biopsy-proved dermatitis herpetiformis (DH) in 3 patients. The first, a 65-year-old woman with seropositive rheumatoid disease, developed arthritis in 1971 and DH in 1976. Our second patient (aged 64), also seropositive, developed RA 1 year after the appearance of DH, while the third patient (aged 49), who is seronegative, had RA for 18 years prior to the emergence of DH. While their dermatological symptoms have been well controlled with dapsone, all patients have experienced continuing active synovitis. The second patient has minimal histological change on small bowel biopsy, and hypothyroidism without thyroid autoantibodies.

An association between adult coeliac disease and RA (Lancaster-Smith, et al., 1974) and between DH and SLE has been noted elsewhere (Moncada, 1974; Davies et al., 1976; and Aronson et al., 1979). Dermatitis herpetiformis is a relatively rare disease. It appears therefore that this association between 2 diseases involving major immunological perturbations may be more than fortuitous.

R. S. ROTHWELL
J. S. PERCY
PAUL DAVIS
Rheumatic Disease Unit,
University of Alberta Hospital,
Edmonton, Alberta T6G $2 G 3$,
Canada

References

Aronson, A. J., Soltani, K., Aronson, O. K., and Ong, R. T. (1979). Systemic lupus erythematosus and dermatitis herpetiformis: concurrence with Marfan's syndrome. Archives of Dermatology, 115, 68-70.

Davies, M. G., Marks, R., and Nuki, G. (1978). Dermatitis herpetiformis (DH): associated immunological disorders. Annals of the Rheumatic Diseases, 37, 574-575.

Davies, M. G., Marks, R., and Waddington, E. (1976). Simultaneous systemic lupus erythematosus and dermatitis herpetiformis. Archives of Dermatology, 112, 1292-1294.

Lancaster-Smith, M. J., Perrin, J., Swarbrick, E. T., and Wright, J. T. (1974). Coeliac disease and autoimmunity. Postgraduate Medical Journal, 50, 45-48.

Moncada, B. (1974). Dermatitis herpetiformis: in association with systemic lupus erythematosus. Archives of Dermatology, 109, 723-725. 